\title{
Radical Scavenging and Radiomodulatory Effects of Psoralea corylifolia Linn. Substantiated by in vitro Assays and EPR Spectroscopy
}

Rajesh Arora ${ }^{\mathrm{a}, \mathrm{b}, *}$, Atlar Singh Dhaker ${ }^{\mathrm{b}}$, Manish Adhikari ${ }^{\mathrm{b}}$, Jyoti Sharma ${ }^{\mathrm{b}}$, Raman Chawla $^{\mathrm{b}}$, Damodar Gupta ${ }^{\mathrm{b}}$, Antoaneta Zheleva ${ }^{\mathrm{a}}$, Yanka Karamalakova ${ }^{\mathrm{a}}$, Raj Kumar ${ }^{\mathrm{b}}$, Raj K. Sharma ${ }^{\mathrm{c}}$, Ashok Sharma ${ }^{\mathrm{b}}$, Sarwat Sultana ${ }^{\mathrm{d}}$, Rajendra P. Tripathi ${ }^{\mathrm{b}}$, Rakesh K. Sharma ${ }^{\mathrm{b}}$, and Veselina Gadjeva ${ }^{\mathrm{a}}$

a Department of Chemistry and Biochemistry, Medical Faculty, Trakia University, Armeiska St. 11, Stara Zagora 6000, Bulgaria

b Institute of Nuclear Medicine and Allied Sciences, Defence Research and Development Organization (DRDO), Brig S. K. Mazumdar Marg, Delhi - 110054, India.

Fax:+91-011-23919509. E-mail: rajesharoradr@rediffmail.com

c Peoples College of Medical Sciences, Bhopal - 462037, India

d Department of Medical Elementology and Toxicology, Jamia Hamdard, New Delhi - 110062, India

* Author for correspondence and reprint requests

Z. Naturforsch. 66 c, 35-46 (2011); received March 6/September 26, 2010

The present study is the first report of the radiomodulatory effects of Psoralea corylifolia Linn. The extract (IBG-RA-26) prepared from P. corylifolia was chemically analysed by HPLC, LC-MS/MS and NMR. The total polyphenolic content of IBG-RA-26 was $0.287 \mathrm{mg} /$ $\mathrm{ml}$ of quercetin equivalents. IBG-RA-26 exhibited a dose-dependent increase in 2,2-diphenyl-1-picrylhydrazyl (DPPH) radical scavenging activity. It exhibited comparable (>50\%) site-specific and non-site-specific hydroxyl radical scavenging activity in higher concentration ranges $(500-1000 \mu \mathrm{g} / \mathrm{ml})$, while at lower concentrations $(5-50 \mu \mathrm{g} / \mathrm{ml})$ it exhibited significantly $(p<0.05)$ higher non-site-specific scavenging ability compared to site-specific activity. Nitric oxide scavenging activity of IBG-RA-26 (5-1000 $\mu \mathrm{g} / \mathrm{ml})$ increased in a concentrationdependent manner, while maximum superoxide ion scavenging ability $(79 \%)$ was observed at $50 \mu \mathrm{g} / \mathrm{ml}$. The electron donation potential of IBG-RA-26 was found to be higher than that of ascorbic acid at lower concentrations (up to $5 \mu \mathrm{g} / \mathrm{ml}$ ). Analysis of the ability of IBGRA-26 to protect membranes against $\gamma$-radiation, utilizing an artificial membrane system (liposome), revealed a significant $(p<0.05)$ decrease in the formation of malondialdehyde (MDA) as a function of the concentration of IBG-RA-26. Radiation-induced lysis of human erythrocytes was monitored and efficacy of IBG-RA-26 was tested in the concentration range $25-1000 \mu \mathrm{g} / \mathrm{ml}$, with significant protective efficacy observed in the range $25-50 \mu \mathrm{g} / \mathrm{ml}$. IBG-RA-26 rendered significant $(p<0.05)$ protection against radiation $(0.25 \mathrm{kGy})$-induced DNA damage. EPR spectroscopy was used to investigate the DPPH radical scavenging capacity of IBG-RA-26. IBG-RA-26 exhibited a good DPPH radical scavenging capacity in a concentration-dependent manner. By direct EPR spectroscopy we have also demonstrated the possible formation of free radical species in a solution of IBG-RA-26. The wide spectrum of radioprotective and antioxidant properties exhibited by IBG-RA-26 indicate that $P$. corylifolia has potential as a radiomodulatory agent.

Key words: Psoralea corylifolia, Radiomodulation, Antioxidant Properties, DNA Protection

\section{Introduction}

Natural plant products, including dietary agents, contain a plethora of bioactive compounds with a diverse array of biological properties. These can be used very effectively for a wide spectrum of scientific applications contrary to their synthetic counterparts. Recent reports have established the utility of natural plant products as radioprotective and radiorecovery agents that can effectively tackle radiation-induced oxidative stress (Arora et al., 2005, 2006, 2007; Arora, 2008).

Psoralea corylifolia Linn. (Fabaceae), commonly known as Babchi or Bakuchi, is an annual herbaceous plant that is widely distributed throughout India, especially in plains of South- 
East Asia. The plant has been used as an integral part of traditional medicine, including Ayurveda, for the treatment of disorders like asthma, cough, nephritis, and calvities, painful lower back, psoriasis, enuresis, alopecia, leukoderma (vitiligo), and premature ejaculation (Miura et al., 1996; Peng et al., 2006; Liu et al., 2004; Panda, 2005). A number of pharmacological activities have been attributed to the plant. P. corylifolia is used for developing prophylactic agents against osteoporosis, and it also exhibits antiplatelet, antihelminthic and antimicrobial activity (Tsai et al., 1996; Zaidi et al., 2009). Significant inhibitory effects on nitric oxide (NO) production have been reported for its methanolic (MeOH) extract (Lee et al., 2005). Cytotoxic, anticancer, and immunomodulatory properties of the seeds of $P$. corylifolia and antifertility properties of the non-saponified fraction of seeds have also been studied in animal model systems (Latha and Panikkar, 1999). The plant possesses chemical constituents such as flavones, furanocoumarins, chalcones, and coumesterol. The seeds contain essential oil, non-volatile terpenoid oil, resin, raffinose, and coumarin compounds, viz., psoralen and isopsoralen, psoralidin, corylifolean, and isopsoralidin (Kapoor, 2001). On the other hand, seed oil contains limonene, $\beta$-caryophyllenoxide, 4-terpineol, linalool, geranylacetate, angelicin, psoralen, and bakuchiol (Gupta et al., 1979). Daidzein, trilaurin, angelicin, psoralen, and sitosterol are essential constituents of its roots (Kapoor, 2001). Bakuchiol, a phenolic constituent of seeds, possesses anti-inflammatory activity with protective activity against oxidative damage to cellular macromolecules like lipids and proteins (Adhikari et al., 2003). The stereoisomer (+)-bakuchiol was found to be the active principle with antitumoural ability and mild level cytotoxicity against five kinds of cultured human cancer cell lines (Ryu et al., 1992). Psoralen and isopsoralen also exhibit dose-dependent anticancer effects on four (KB, KBv200, K562, and K562/ADM) cell lines (Wang et al., 2009). The oil exhibits a distinct stimulatory action on voluntary muscles. It increases the tone of the uterus and stimulates the intestinal smooth muscles of experimental animals. Isopsoralen exhibits tranquilosedative, anticonvulsant, and central muscle-relaxant properties in rats, mice, and rabbits (Chandhoke and Ray Ghatak, 1975). The manifold uses of Psoralea in medicine, including antioxidant, antitumoural, immunomodulatory, and anti-inflammatory activities, which are relevant to radioprotection, formed the scientific basis for undertaking the present studies. We have proven the free radical scavenging and radiomodulatory activites by in vitro/ex vivo experimentation and electron paramagenetic resonance (EPR) spectroscopy.

\section{Material and Methods}

\section{Collection of plant material}

Fresh seeds of Psoralea corylifolia were collected from plants growing in Bhopal, Madhya Pradesh, India. The plant specimen was authenticated by the first author. A voucher specimen (Specimen No. INM/RA/IBG-RA-26) has been deposited at the Institute of Nuclear Medicine and Allied Sciences (INMAS), Delhi, India.

\section{Preparation of plant extract}

The air-dried seeds of $P$. corylifolia were ground into a coarse powder. $500 \mathrm{~g}$ of the powdered material were suspended in 21 of distilled water and subjected to cold maceration for $24 \mathrm{~h}$. Then, the extract was filtered through muslin cloth, and the filtrate was evaporated under reduced pressure and vacuum-dried. The yield of the extract (IBG-RA-26) was $10-15 \%$ of the dry weight of the seeds of $P$. corylifolia.

\section{HPLC conditions}

The analyses were performed on a Shimadzu liquid chromatograph with a ternary solvent system model LC-6AD, combined with a UV-Vis detector model SPD-6AV (Shimadzu Co., Kyoto, Japan), and a Rheodyne injection valve fitted with an 100-ml sample loop. A microcomputer equipped with Microquimica MQI18PCA software was used for recording chromatograms and measuring peak areas. HPLC separation of the psoralens was performed using a Shimadzu octadecyl Shim-pack CLC-ODS (4.6 mm i.d., $25 \mathrm{~cm}$ long, and $5 \mathrm{~mm}$ long particles) reverse-phase column with a small pre-column $(4.6 \mathrm{~mm}$ i.d., $2.5 \mathrm{~cm}$ long) containing the same packing, used to protect the analytical column. Before use, the solvent was filtered through a $0.45-\mu \mathrm{m} \mathrm{HV}$ filter (Millipore, Billeriza, USA), and then degassed for $20 \mathrm{~min}$ in an ultrasonic bath. Elution was performed with acetonitrile/water $(55: 45, \mathrm{v} / \mathrm{v})$ at a flow rate of $1.0 \mathrm{ml} / \mathrm{min}$. Aliquots of $10 \mathrm{ml}$ were injected with a 25-ml Hamilton (Bonaduz, Switzerland) syringe. 
After determination the column was recorded for 10 min with the same solvent system and flow rate. Absorbance was recorded at $223 \mathrm{~nm}$. All chromatographic analyses were performed at $22{ }^{\circ} \mathrm{C}$.

\section{Liquid chromatography-mass spectrometry/mass} spectrometry (LC-MS/MS)

For LC-MS/MS a Varian (Palo Alto, USA) model 410 Prostar Binary LC instrument with 500 MS IT PDA detectors was used. Direct infusion mass with ESI and APCI negative and positive ionization mode, mass ranging from 50 to $2000 \mathrm{~m} / z$ LC-MS/MS and MSn ION. The operating conditions were optimized for the MS/MS analyses of compounds in the extract.

\section{NMR spectroscopy}

A model Mercury Plus $300 \mathrm{MHz}$ NMR spectrometer (Bruker, Rheinstetten, Germany) was used with $5 \mathrm{~mm}$ autoswitchable probe with PFG $\left({ }^{1} \mathrm{H}\right)$.

\section{Irradiation}

Blood was drawn from volunteers, amongst the authors, and subjected to radiation $(0.1 \mathrm{kGy})$. A $0.25-\mathrm{kGy}$ radiation dose was delivered to study the membrane protection activity in an artificial membrane system (liposomes), delivered from a ${ }^{60} \mathrm{Co}$ gamma chamber [Gamma Cell 5000, Board of Radiation and Isotope Technology (BRIT), Mumbai, India] at a dose of $1.93 \mathrm{kGy} / \mathrm{h}$. Dosimetry was carried out using a Baldwin Farmer's secondary dosimeter (North Baldwin, New York, USA) and Fricke's chemical dosimetry method (Grant et al., 1976).

\section{Estimation of total polyphenolic content}

The polyphenolic content was estimated using the method of Singleton and Rossi (1965) with some modification as described previously (Adhikari et al., 2010). Folin-Ciocalteu reagent (FCR) and $20 \%$ sodium carbonate solution were made to react with IBG-RA-26 (concentration of stock solution $=1 \mathrm{mg} / \mathrm{ml}$ ). Absorbance was recorded at $700 \mathrm{~nm}$ after $30 \mathrm{~min}$, using a $\mu \mathrm{Quant}^{\mathrm{TM}}$ microplate spectrophotometer (BioTek Instruments, Inc., Highland Park, Whinooski, VT, USA).

\section{DPPH radical scavenging activity}

The radical scavenging activity of IBG-RA-26 $(25-1000 \mu \mathrm{g} / \mathrm{ml})$ against the stable DPPH (2,2-di- phenyl-1-picrylhydrazyl) radical was determined spectrophotometrically (Cuendet et al., 1977). The assay was carried out in triplicate and percent inhibition was calculated using the following formula: \% inhibition $=[$ (O.D. control - O.D. sample)/O.D. control] · 100, where O.D. sample is the absorbance of the sample and O.D. control is the absorbance of the control at $517 \mathrm{~nm}$.

\section{Hydroxyl radical scavenging activity}

The hydroxyl radical scavenging potential (sitespecific/non-site-specific) was measured using the deoxyribose degradation assay (Halliwell et al., 1987). Solutions with different concentrations of IBG-RA-26 $(5-1000 \mu \mathrm{g} / \mathrm{ml})$ were mixed with the reaction mixture as described previously (Sagar et al., 2006), and the percentage inhibition of degradation of deoxyribose or hydroxyl radical scavenging potential was evaluated as described above.

\section{Nitric oxide ion scavenging potential}

The nitric oxide ion scavenging potential of IBG-RA-26 $(2.5-1000 \mu \mathrm{g} / \mathrm{ml})$ was evaluated using the methodology described by Green et al. (1982). $5 \mathrm{~mm}$ aqueous sodium nitroprusside, used to generate nitric oxide at physiological $\mathrm{pH}$ which interacts with oxygen to generate nitrite ions, was reacted with Griess reagent ( $1 \%$ sulfanilamide in $5 \%$ phosphoric acid, $0.1 \% N$-1-naphthylethylenediamine dihydrochloride in water). The nitric oxide scavenging activity was evaluated as decrease in percent absorbance of the chromogen formed by diazotation of nitrite with sulfanilamide and subsequent coupling with naphthylethylenediamine recorded at $546 \mathrm{~nm}$.

\section{Superoxide radical scavenging potential}

The superoxide radical quenching ability of IBG-RA-26 $(0.5-50 \mu \mathrm{g} / \mathrm{ml})$ was determined using the nitroblue-tetrazolium reduction assay (Kakkar et al., 1984). The intensity of the formed chromogen (in the $n$-butanol layer) was measured at $560 \mathrm{~nm}$, and percentage inhibition of chromogen formation was evaluated in terms of \% inhibition.

\section{Antioxidant activity}

The antioxidant activity in the aqueous phase or reducing power of IBG-RA-26 (2.5-500 $\mu \mathrm{g} /$ 
$\mathrm{ml}$ ) was determined using the potassium ferricyanide reduction assay (Oyaziu, 1986) as described previously (Chawla et al., 2005). The antioxidant activity (aqueous phase) of IBG-RA-26 and ascorbic acid (used as positive control) was compared.

\section{Protection of membrane against radiation damage (membrane protection index)}

Soyalecithin (phospholipid) and cholesterol (1:1 molar ratio) were suspended in an appropriate amount of chloroform. A thin film was developed by complete evaporation of chloroform in a rotary evaporator (Büchi, Newcastle, USA) at $40{ }^{\circ} \mathrm{C}$. The film was subjected to hydration in PBS (phosphate buffered saline, $0.1 \mathrm{M}, \mathrm{pH} 7.4$ ) and incubated in a shaking water bath $\left(40^{\circ} \mathrm{C}\right)$ for $4 \mathrm{~h}$. The stock solution was then diluted with PBS (0.1 M, pH 7.4) to the final concentration in terms of phospholipid content (New et al., 1990). Differently treated samples, i.e. liposome only (untreated), radiation only ( $0.25 \mathrm{kGy})$, liposome + IBG-RA-26, and liposome + IBG-RA-26 + 0.25 $\mathrm{kGy}$, were evaluated for the levels of malondialdehyde (MDA), an end product of membrane degeneration. A radiation dose of $0.25 \mathrm{kGy}$ at a dose rate of $1.93 \mathrm{kGy} / \mathrm{h}$ was used, and after exposure the samples were incubated for $1 \mathrm{~h}$ at $37^{\circ} \mathrm{C}$. The equivalent volumes of $10 \%$ TCA (trichloro acetic acid) and $0.5 \%$ thiobarbituric acid in $0.025 \mathrm{~m} \mathrm{NaOH}$ were added. The resultant mixture was then heated at $80^{\circ} \mathrm{C}$ for $1 \mathrm{~h}$ in a water bath. A pink coloured chromogen complex so formed was read at $535 \mathrm{~nm}$.

\section{Antihemolytic activity}

Erythrocyte suspensions were prepared in $0.14 \mathrm{M} \mathrm{NaCl}$ according to Daice and Lewis (1995). Washed erythrocyte suspensions were pre-incubated with $2 \mathrm{~mm}$ sodium azide for $1 \mathrm{~h}$ at $37^{\circ} \mathrm{C}$ in a shaking water bath to inhibit any activity of catalase. Equal volumes of the erythrocyte suspension in PBS were taken, and different concentrations $(25-1000 \mu \mathrm{g} / \mathrm{ml})$ of IBG-RA-26 were added $30 \mathrm{~min}$ prior to irradiation $(0.1 \mathrm{kGy})$ and thereafter further incubated for $1 \mathrm{~h}$ at $37^{\circ} \mathrm{C}$. There were four experimental groups: (a) untreated; (b) radiation only ( $0.1 \mathrm{kGy})$; (c) IBG-RA-26 only; (d) IBG-RA-26 + radiation (0.1 kGy). The antihemolytic activity of IBG-RA-26 was evaluated in terms of protection against membrane degen- eration or lipid peroxidation activity (Srour et al., 2000).

\section{Modulation of radiation-induced DNA damage}

Radiation-induced DNA damage was assessed electrophoretically using a modified method of Sambrook et al. (1989). To evaluate the radioprotective efficacy of IBG-RA-26, pBR322 plasmid DNA $(100 \mu \mathrm{g} / \mathrm{ml})$ was mixed with different concentrations of IBG-RA-26 along with $\mathrm{KH}_{2} \mathrm{PO}_{4}$ buffer (10 mM, pH 7.4). The reaction mixture was exposed to irradiation $(0.25 \mathrm{kGy})$ at a dose rate of $1.93 \mathrm{kGy} / \mathrm{h}$. The final reaction mixture was then incubated for $1 \mathrm{~h}$ at $37^{\circ} \mathrm{C}$. The sample, along with the loading dye of $0.25 \%$ bromophenol blue, $15 \%$ sucrose, and $0.25 \%$ xylene cyanol FF in water, was loaded onto an $1 \%(w / v)$ agarose gel. Electrophoresis was carried out at $50 \mathrm{~V}$ in a DNA submarine electrophoresis unit (Bangalore Genie, Bangalore, India). The agarose gel was stained with ethidium bromide $(0.5 \mu \mathrm{g} / \mathrm{ml}$ distilled water $)$ for $30 \mathrm{~min}$. The ethidium bromide-stained DNA bands were visualized under ultraviolet light using a UV transilluminator (UVP, Hercules, CA, USA). The pictures were analysed densitometrically using the Bio-Rad GEL-DOC system (BioRad, USA). The percent retention of supercoiled form (\%SC) represented protection, while the percentage of open circular form (\%OC) represented DNA damage and was evaluated using the integrated density values (IDV) of bands as follows: $\%$ SC $=[$ SCIDV/(SCIDV + OCIDV $)] \cdot 100$.

\section{Electron paramagnetic resonance (EPR) studies}

For all EPR experiments, an EMX ${ }^{\text {micro }}$ EPR spectrometer (Bruker, Rheinstetten, Germany) equipped with a standard resonator working at a frequency in the X-band region was used. Quartz capillaries were used as sample tubes. All EPR spectra were recorded at room temperature. Spectral processing was performed using Bruker WIN-EPR and Simphonia software.

\section{Direct EPR spectroscopy study on IBG-RA-26 aqueous solutions}

Quartz capillaries were filled with $50 \mathrm{~mm}$ IBGRA-26 (with psoralen, main component of $P$. corylifolia, as marker and its equivalent concentration) dissolved in deionized water and placed in the EPR cavity. EPR spectrometer settings 
were as follows: center field, $3529.50 \mathrm{G}$; microwave power, $20.61 \mathrm{~mW}$; modulation amplitude, $10.00 \mathrm{G}$; sweep width, $200.00 \mathrm{G}$; receiver gain, 2 . $10^{3}$; time constant, $1310.72 \mathrm{~ms} ; 1$ scan per sample.

\section{EPR study of DPPH radical scavenging capacity of IBG-RA-26}

Determination of the scavenging capacity of IBG-RA-26 was based on the decay of the DPPH EPR signal after addition of the test sample to the stock solution of DPPH. The scavenging capacity of IBG-RA-26 was studied in the concentration range 5-60 $\mathrm{mm}$ (psoralen equivalent concentration). Mixtures containing $250 \mu \mathrm{l}$ of stock ethanol solution of DPPH $(80 \mu \mathrm{m})$ and $10 \mu \mathrm{l}$ of IBGRA-26 were stirred and, after 10 min incubation in the dark, were immediately transferred into capillaries and placed in the microwave cavity of the EPR spectrometer. Every concentration was studied in triplicate at room temperature $\left(22^{\circ} \mathrm{C}\right)$. The decay of the DPPH signal was monitored and compared with that of the blank sample, containing $250 \mu \mathrm{l}$ of DPPH plus $10 \mu \mathrm{l}$ of water. DPPH radical scavenging capacity of the tested samples was calculated according to the following equation: scavenged DPPH radical $(\%)=\left[\left(\mathrm{I}_{\mathrm{o}}-\mathrm{I}\right) / \mathrm{I}_{\mathrm{o}}\right]$ $\cdot 100$, where $I_{o}$ is the double integral intensity of DPPH signal for the blank sample, and I is the double integral intensity of the studied sample measured after addition of DPPH scavenger.

\section{Results and Discussion}

Reactive oxygen species (ROS) play a dual role in maintaining metabolic homeostasis in the body. These radicals are generated during mitochondrial electron transport, microsomal P450-dependent reactions, and non-enzymatic and enzymatic metabolism of dopamine (Rani et al., 2004; Saito et al., 2007). Free radical generation can be advantageous in systems like blastocyst implantation, iodination of tyrosine in thyroxine biosynthesis and mucous secretion in goblet cells (Sies, 1993). The imbalance of the generation of ROS relative to inactivation caused by internal/external effects/ stimuli or by radiation stress leads to oxidative stress. Such free radical-mediated oxidative stress has been implicated in more than 100 diseased states (Halliwell and Gutteridge, 1990) including acute radiation sickness syndrome. The progressive damage induced by free radicals leads to li-

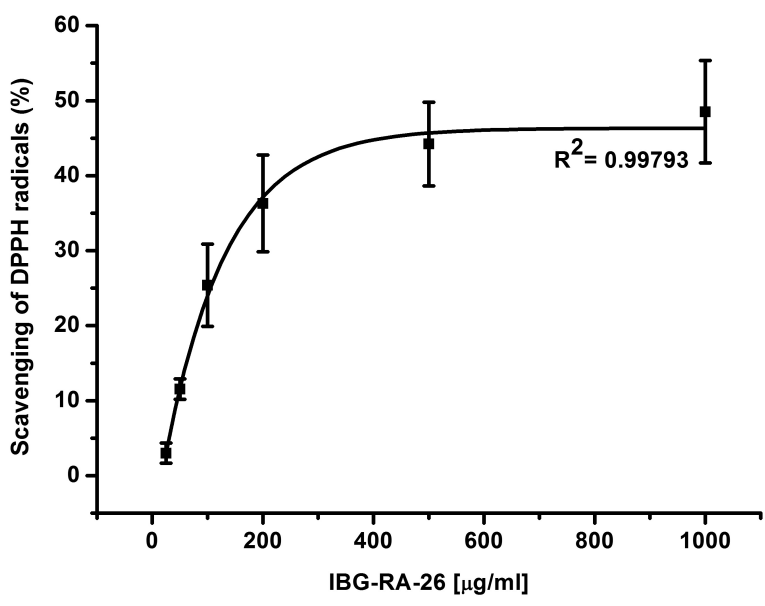

Fig. 1. Percent scavenging of DPPH radicals as a function of IBG-RA-26 concentration.

pid peroxidation (Lai et al., 2001), DNA damage etc., which can be retarded by exogenous supplementation with antioxidants (Lai et al., 2001) of both natural and synthetic origin.

Three major and seven minor compounds were found to be present in IBG-RA-26. Psoralen was identified upon analysing the fragmentation patterns in the mass spectra $\left(M_{r} 186.16\right)$ as one of the major constituents in the IBG-RA-26 sample. Similar results have been reported by various researchers (Liu et al., 2004; Wang et al., 2009).

In the present study, the free radical modulatory potential of $P$. corylifolia Linn. was evaluated. More than $45 \%$ scavenging was observed in case of DPPH and both site-/non-site-specific hydroxyl radical scavenging activity at $\geq 500 \mu \mathrm{g} / \mathrm{ml}$ of IBGRA-26. In DPPH radical scavenging, the antiradical power of IBG-RA-26 was evaluated as the decrease in absorbance of DPPH radicals at $517 \mathrm{~nm}$ (Fig. 1). IBG-RA-26 donated hydrogen to form a stable DPPH molecule. In the radical form, this molecule has an absorbance at $517 \mathrm{~nm}$, which disappears after acceptance of an electron or hydrogen radical from the natural plant product to become a stable diamagnetic molecule (Matthäus, 2002). Ferrous ions facilitate the production of ROS and their chelation is one of antioxidative effects by virtue of retarding metal-catalyzed oxidation (Cousins et al., 2007).

IBG-RA-26 exhibited comparable (> 50\%) non-site-specific and site-specific hydroxyl radical scavenging activity in the highest tested range $(200-1000 \mu \mathrm{g} / \mathrm{ml})$ (Figs. 2A, B). Site-specific hy- 

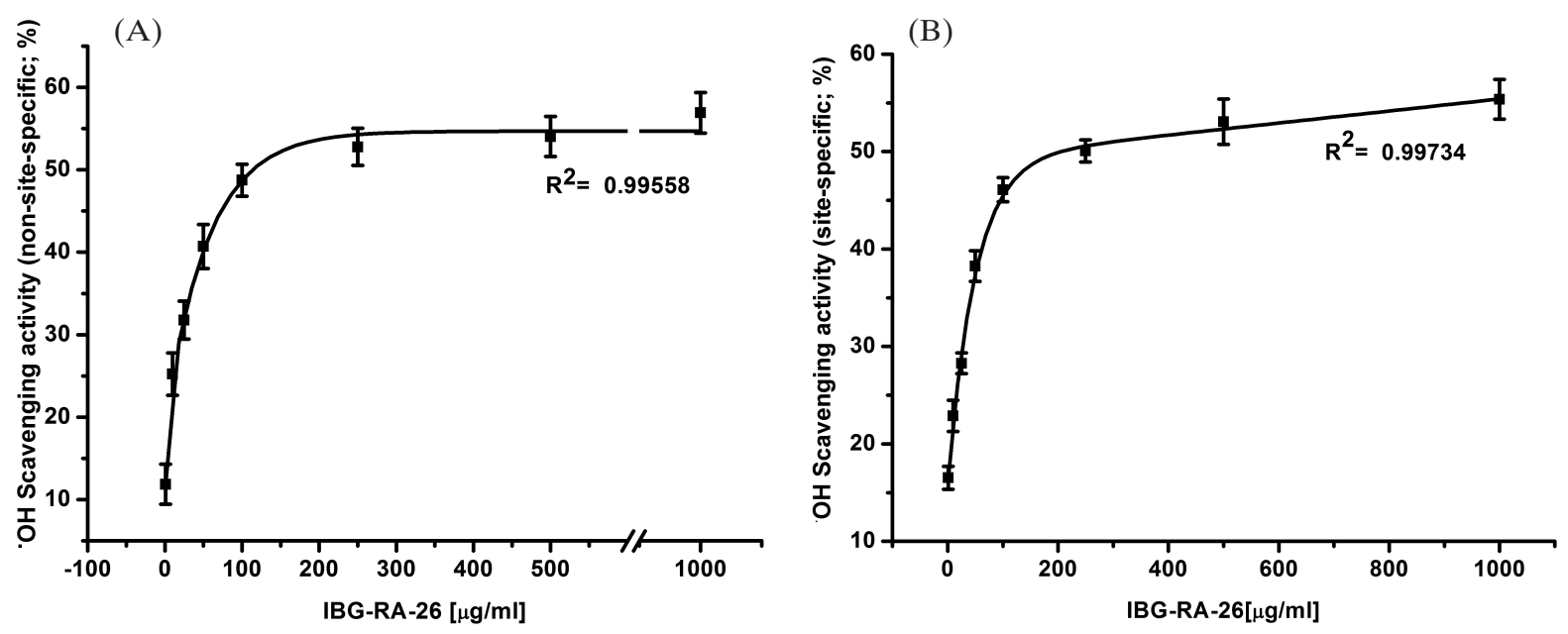

Fig. 2. (A) Non-site-specific and (B) site-specific scavenging of hydroxyl radicals. In the lower concentration range $(5-50 \mu \mathrm{g} / \mathrm{ml})$, IBG-RA-26 exhibited significantly $(p<0.05)$ higher non-site-specific scavenging ability as compared to site-specific scavenging ability.

droxyl radical scavenging activity of IBG-RA-26 indicates its metal chelation potential. In the sitespecific assay, EDTA is not used; thus degradation of deoxy-D-ribose is primarily done by the ferrous ion itself. At lower concentration range $(5-50 \mu \mathrm{g} / \mathrm{ml})$, IBG-RA-26 exhibited significantly $(p<0.05)$ higher non-site-specific scavenging ability (Fig. 2A), compared to site-specific scavenging ability, exhibiting its potential to restrict free radical-mediated oxidative stress. In addition, the nitric oxide scavenging activity of IBG-RA-26 (tested concentration range $5-1000 \mu \mathrm{g} / \mathrm{ml}$ ) was

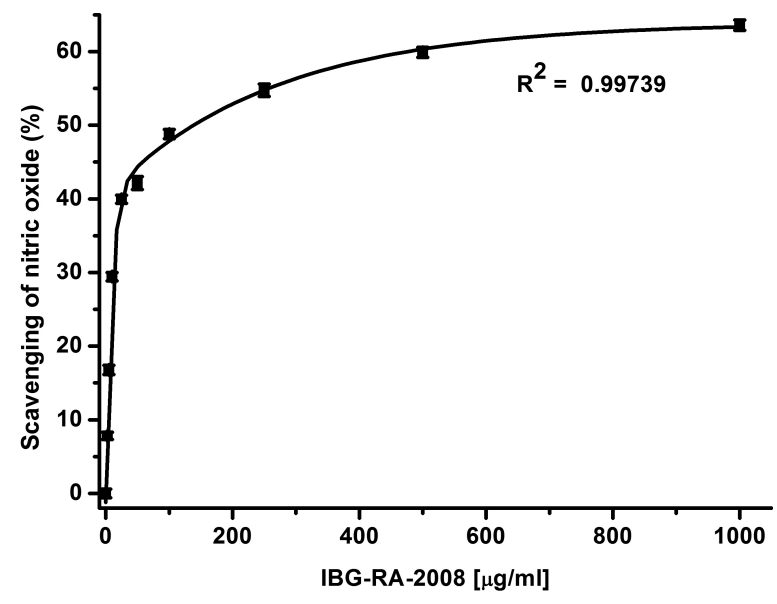

Fig. 3. Nitric oxide scavenging potential of IBG-RA-26 as a function of its concentration. found to increase as a function of its concentration $\left(R^{2}=0.99739\right)$. It exhibited $50 \%$ nitric oxide scavenging activity at a concentration of $100 \mu \mathrm{g} /$ ml (Fig. 3).

Superoxide is an oxygen-centred radical, a weak oxidant with limited and selected chemical reactivity. It is generated as a primary radical during mitochondrial leaks and may initiate a free radical cascade leading to the generation of hydroxyl radical, singlet oxygen etc. (Halliwell and Chirico, 1993). IBG-RA-26 exhibited $79 \%$ scavenging (Fig. 4) in a concentration-dependent manner

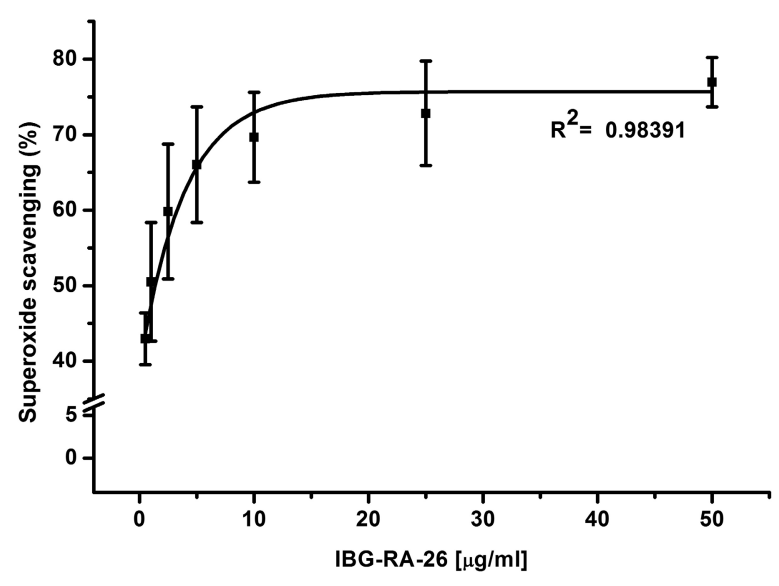

Fig. 4. Superoxide scavenging potential of IBG-RA-26 as a function of its concentration. 


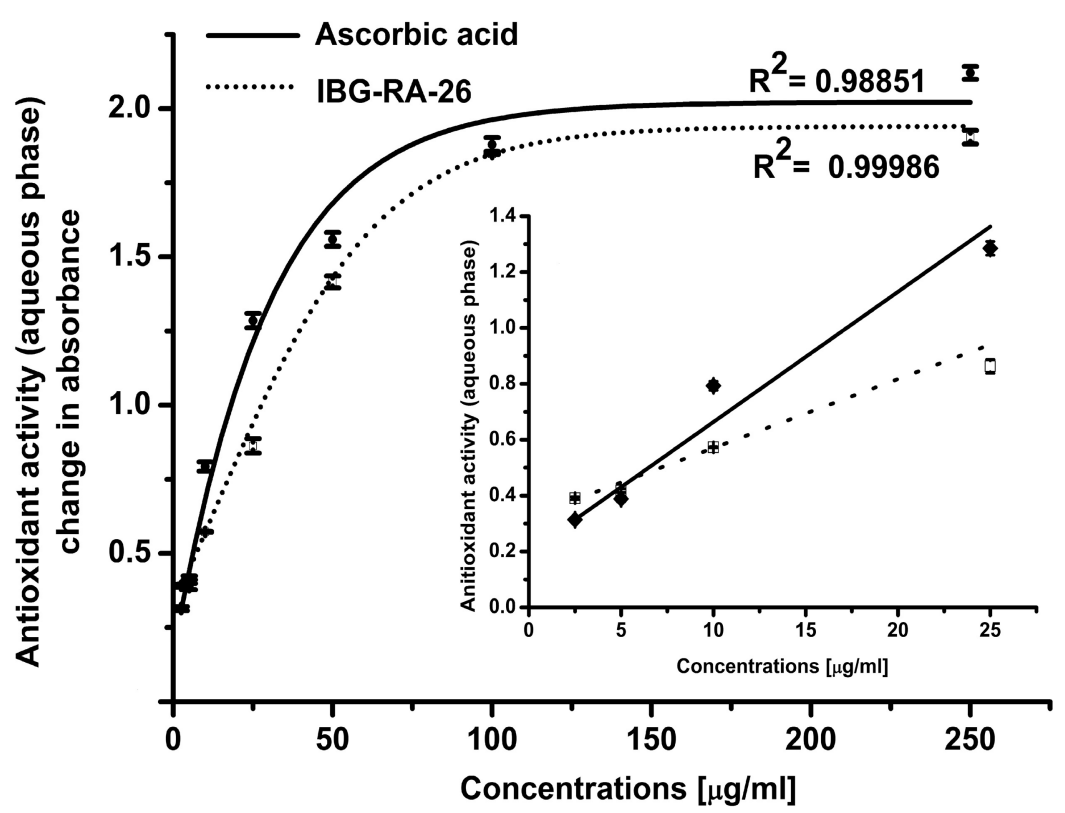

Fig. 5. Antioxidant activity of IBG-RA-26 as a function of its concentration $(0-250 \mu \mathrm{g} / \mathrm{ml})$ in the aqueous phase, in comparison with ascorbic acid. Inset: Enlarged section of concentration range $0-25 \mu \mathrm{g} / \mathrm{ml}$.

$\left(R^{2}=0.98391\right)$ ranging between $0.5-50 \mu \mathrm{g} / \mathrm{ml}$, i.e. at one tenth the dose at which hydroxyl radical scavenging is observed.

Antioxidant activity (aqueous phase) of IBGRA-26 $(2.5-1000 \mu \mathrm{g} / \mathrm{ml})$ was found to increase as a function of its concentration $\left(R^{2}=0.99986\right)$. The electron donation potential of IBG-RA-26 was found to be higher than that of ascorbic acid at lower concentrations up to $5 \mu \mathrm{g} / \mathrm{ml}$; its electron donation potential was comparable to that of ascorbic acid at the concentration of $100 \mu \mathrm{g} /$ $\mathrm{ml}$ (Fig. 5). Reducing power (electron donation potential) is a chemical property of biological importance of natural plant products, and has been investigated in the context of radiation protection (Chawla et al., 2005).

Further, the membrane protecting ability of IBG-RA-26 was evaluated. The reduction in the radiation-induced MDA formation was measured as thiobarbituric acid reactive substances (TBARS) in vitro. The analysis of the membraneprotecting ability of IBG-RA-26, utilizing an artificial membrane system (liposome), revealed a significant $(p<0.05)$ decrease in the formation of MDA with an increase in the concentration of IBG-RA-26 $\left(10-1000 \mu \mathrm{g} / \mathrm{ml} ; R^{2}=0.995\right)$. At concentrations below $10 \mu \mathrm{g} / \mathrm{ml}$ it did not exhibit any significant change in activity. The most effective dose, as compared to the drug only group, was found to be the highest tested concentration, i.e. $1000 \mu \mathrm{g} / \mathrm{ml}$ (Fig. 6A). In addition, radiationinduced lysis of erythrocytes was monitored, and the efficacy of IBG-RA-26 was tested in the concentration range $25-1000 \mu \mathrm{g} / \mathrm{ml}$. A dose-dependent $\left(R^{2}=0.995\right)$ effect was observed (Fig. 6B). As compared to the drug only group, the optimal concentration with least toxicity and maximal protection was found to be $25 \mu \mathrm{g} / \mathrm{ml}$. IBG-RA-26 exhibited increased toxicity at concentrations $\geq 100 \mu \mathrm{g} / \mathrm{ml}$. MDA is known to be mutagenic in bacterial and mammalian cells and carcinogenic in rats (Gandhi and Nair, 2005); hence a reduction of radiation-induced MDA formation is desirable. Erythrocytes are prone to oxidative damage due to the presence of polyunsaturated fatty acids, heme, iron, and oxygen (Rathore et al., 1998). Radiation-induced hemolysis leads to the hemopoietic syndrome, which is a primary cause of lethality in acute radiation sickness syndrome. The radioprotective property has also been exhibited by a number of natural plant products, e.g. Podophyllum hexandrum (Sagar et al., 2006). By virtue of its ability to modulate the hemopoietic system, IBG-RA-26 exhibited similar erythrocyte 

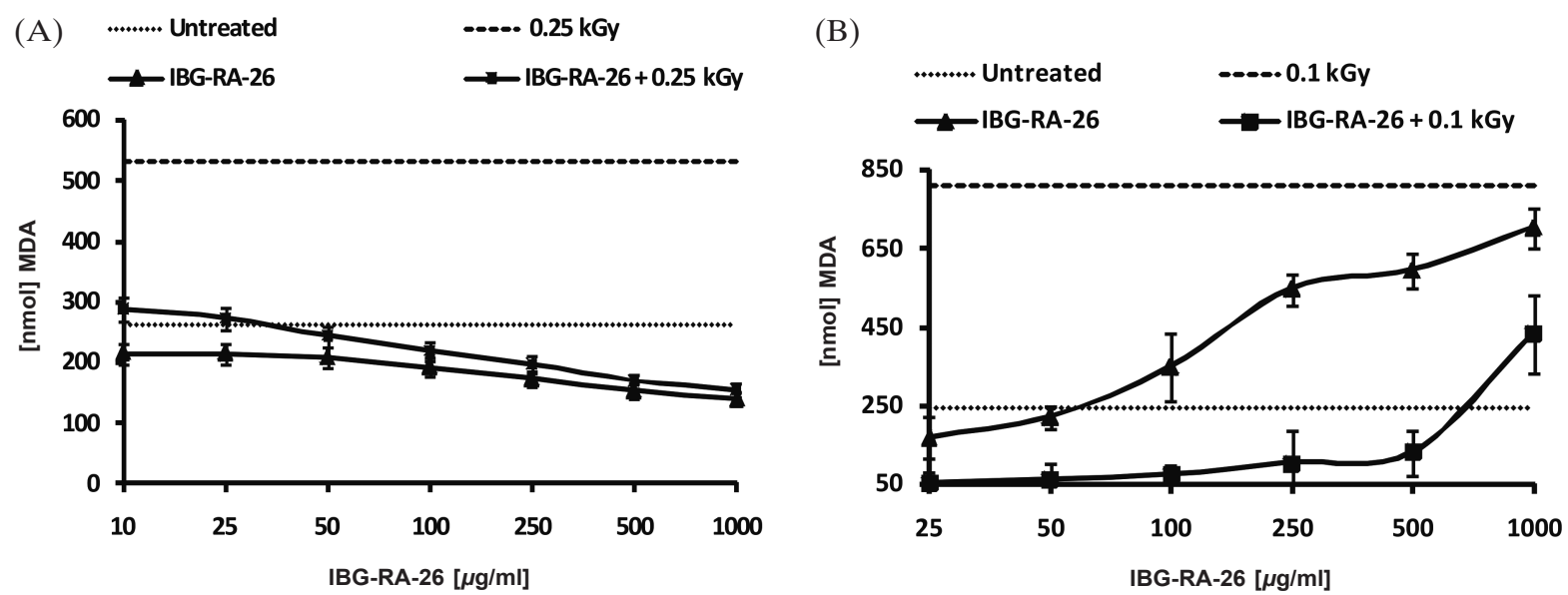

Fig. 6. (A) Analysis of the membrane protecting ability of IBG-RA-26 utilizing an artificial membrane system (liposome). A significant $(p<0.05)$ decrease in the formation of malondialdehyde (MDA) with increasing concentration of IBG-RA-26 $(10-1000 \mu \mathrm{g} / \mathrm{ml})$ was recorded. (B) Effect of different concentrations of IBG-RA-26 on radiation $(0.1 \mathrm{kGy})$-mediated lipid peroxidation evaluated in erythrocytes. Each experiment was performed in triplicate and was repeated three times. The lipid peroxidation activity is expressed as nanomoles of MDA formed.

protection potential against supralethal radiation stress, indicating its significant radiation protection ability in the narrow dose range.

The DNA protecting ability of IBG-RA-26 was investigated using the plasmid relaxation assay, which is a semi-quantitative assessment of ionizing radiation-induced oxidative damage to DNA (Sambrook et al., 1989). Different doses of IBGRA-26 in the range of $10-50 \mu \mathrm{g} / \mathrm{ml}$ were evaluated for their protective efficacy against $\gamma$-radiation,

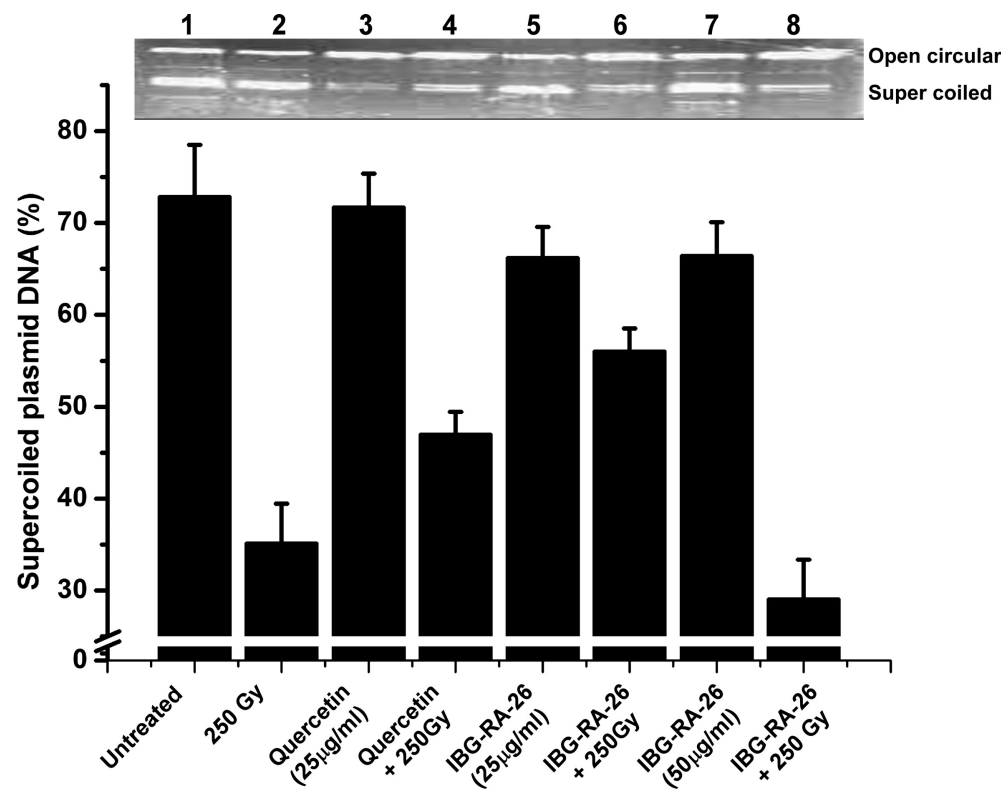

Fig. 7. Evaluation of the DNA protective ability of IBG-RA-26 in terms of percentage of supercoiled form retained after irradiation. Densitometric analysis of pBR322 DNA pretreated for $1 \mathrm{~h}$ with IBG-RA-26 and then irradiated revealed that IBG-RA-26 at a concentration of $25 \mu \mathrm{g} / \mathrm{ml}$ (lane 6) provided significantly higher $(p<0.05)$ retention of supercoiled DNA as compared to the quercetin $(25 \mu \mathrm{g} / \mathrm{ml}$, lane 4)-treated group. 
R. Arora et al. - Radiomodulatory Effects of Psoralea corylifolia Linn.

(A)

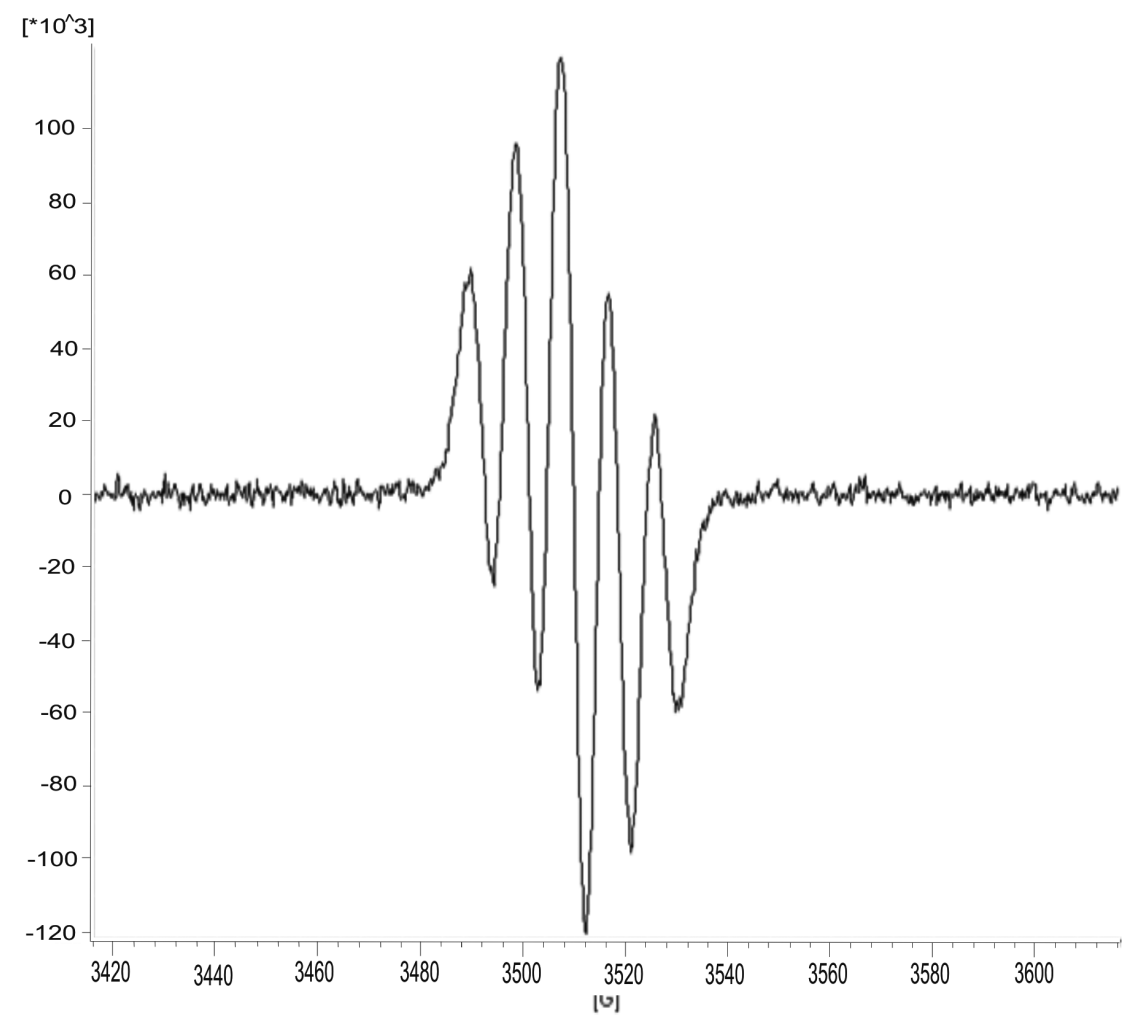

(B)

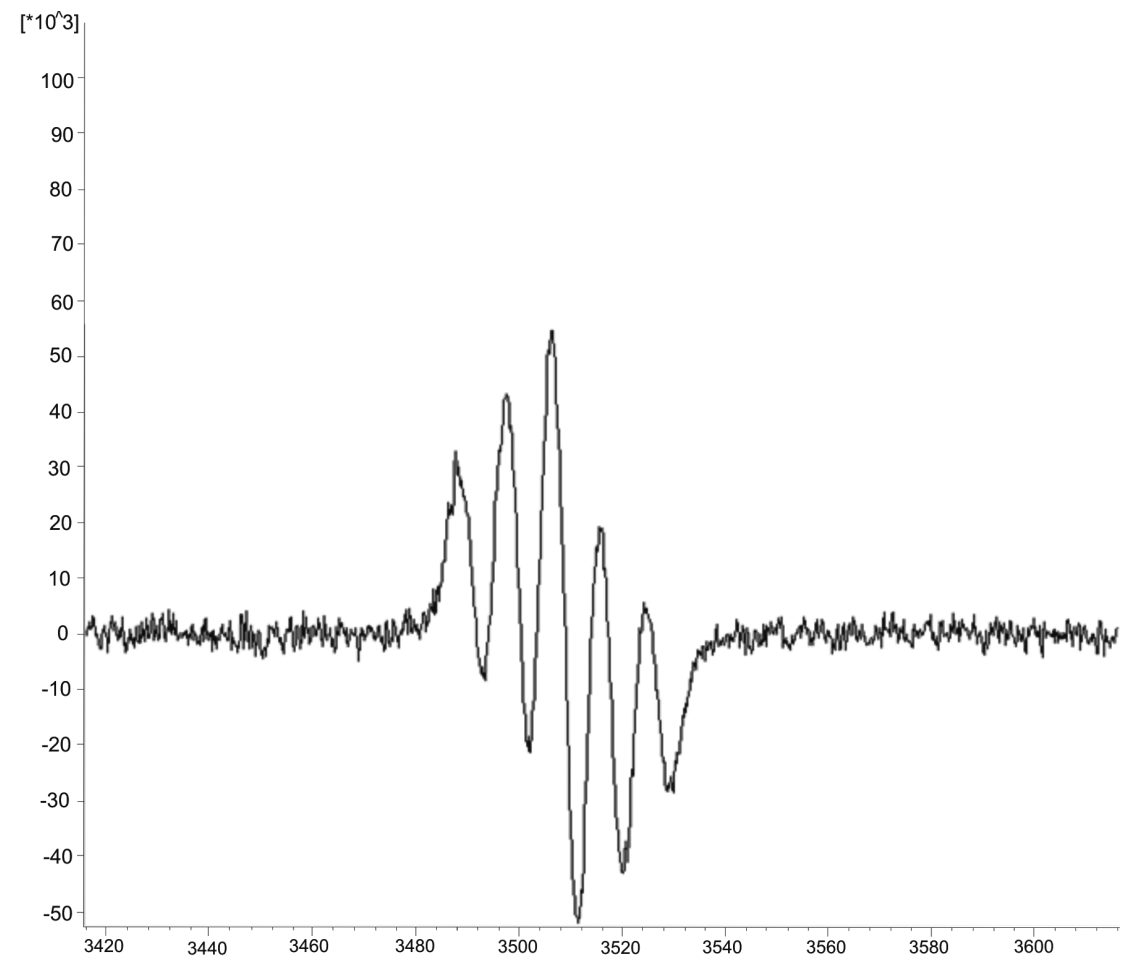


(C)

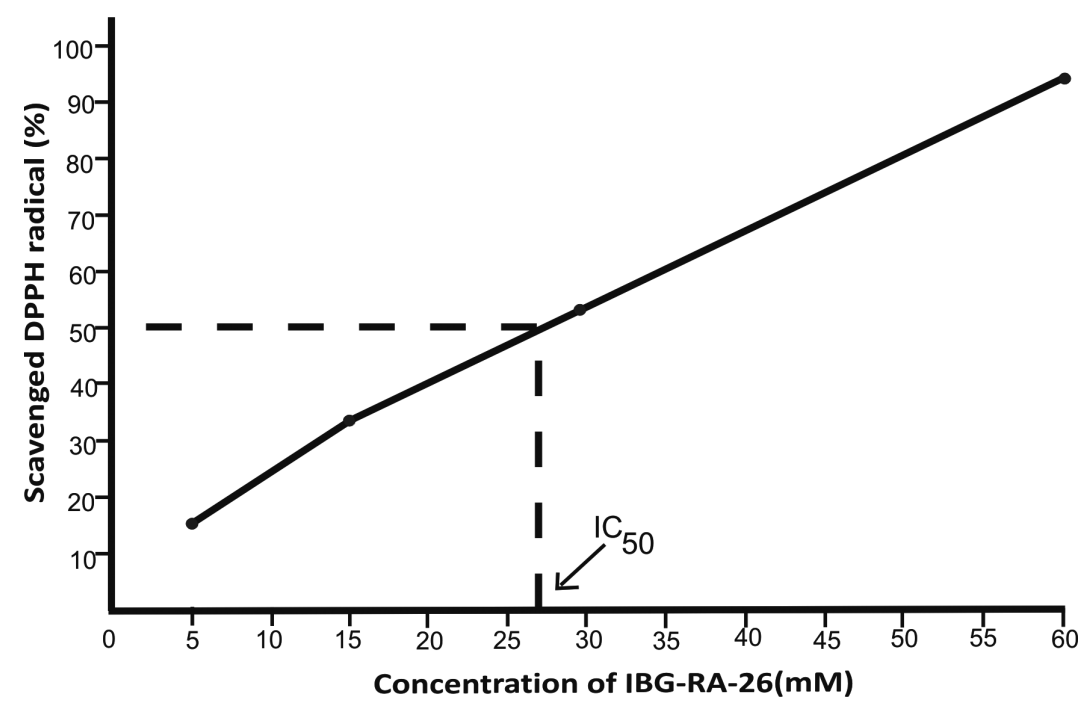

Fig. 8. EPR spectra of DPPH radicals (A) in the blank and (B) in the mixture containing 30 mM of IBG-RA-26. EPR spectrometer settings were as follows: center field, $3516.00 \mathrm{G}$; microwave power, 3.232 mW; modulation amplitude, $5.00 \mathrm{G}$; sweep width, $200.00 \mathrm{G}$; receiver gain, $5.02 \cdot 10^{3}$; time constant, $163.84 \mathrm{~ms}$; 1 scan per sample. (C) DPPH scavenging activity of IBG-RA-26 as a function of its concentration (psoralen equivalent concentration in $\mathrm{mm}$ ) determined using EPR. $\mathrm{IC}_{50}$ was calculated to be $27.7 \mathrm{~mm}$.

in terms of percentage of supercoiled form retained. It can be seen in Fig. 7, that the untreated control (positive control, lane 1) comprised more than $73 \%$ supercoiled form, while upon exposure to $0.25 \mathrm{kGy} \gamma$-radiation (negative control, lane 2), nearly $65 \%$ relaxed form (open circular DNA) was observed. Densitometric analysis of pBR322 DNA pre-treated for $1 \mathrm{~h}$ with IBG-RA-26 and then irradiated revealed that IBG-RA-26 at a concentration of $25 \mu \mathrm{g} / \mathrm{ml}$ (lane 6) led to in retention of $56 \%$ of the supercoiled form, which was significantly higher $(p<0.05)$ than that produced in the quercetin $(25 \mu \mathrm{g} / \mathrm{ml}$, lane 4$)$-treated group, which retained only $47 \%$ supercoiled form. Such membrane and DNA protection ability could be attributed to the polyphenolic content of IBGRA-26, which was found to be $0.287 \mathrm{mg} / \mathrm{ml}$ of quercetin equivalent (standard used for experimentation).

As is seen in Fig. 8A, the EPR spectrum of an ethanol solution of DPPH in the blank sample was characterized by five lines with relative intensities 1:2:3:2:1. The same characteristic EPR spectra of five lines were recorded for the mixtures containing different concentrations of IBGRA-26 (Fig. 8B). For all studied mixtures containing different concentrations of IBG-RA-26, a decrease in the EPR signal integral intensity was registered after $10 \mathrm{~min}$ of incubation with ethanol solution of DPPH, compared to the blank. An almost linear dependence was observed between the increase of concentration of IBG-RA-26 and the decrease of the EPR signal integral intensity of the studied mixture (Fig. 8B).

To estimate the concentration of IBG-RA-26 at which $50 \%$ of the integral intensity of DPPH signal was reduced $\left(\mathrm{IC}_{50}\right)$, a KORELIA DINAMICS programme was used (Yankov, 1998). The experimental data were interpolated with a cubic spline and an $\mathrm{IC}_{50}$ value of $27.7 \mathrm{mM}$ was calculated from the graph (Fig. 8C).

In these preliminary EPR studies we showed that IBG-RA-26 exhibits significant DPPH radical scavenging capacity in a concentration-dependent manner. By direct EPR spectroscopy we have also demonstrated the possible formation of free radical species in a solution of IBG-RA-26. To elucidate the origin of those radicals further extended EPR spectroscopy studies are in progress in our laboratory.

Keeping in view the wide spectrum of radioprotective and antioxidant properties that IBGRA-26 exhibits, it can be concluded that $P$. corylifolia has potential as a radiomodulatory agent. 


\section{Acknowledgement}

Rajesh Arora is grateful to Department of Science and Technology (DST), Government of India, for sponsoring his trip to Trakia University for three months as a Visiting Scientist under the aegis of the Indo-Bulgarian collaborative programme (INT/Bulg/B-57/05). Support from DST, India, and Ministry of Education, Youth and Sci-

Adhikari S., Joshi R., Patro B. S., Ghanty T. K., Chintalwar G. J., Sharma A., Chattopadhyay S., and Mukherjee T. (2003), Antioxidant activity of bakuchiol: Experimental evidences and theoretical treatments on the possible involvement of the terpenoid chain. Chem. Res. Toxicol. 16, 1062-1069.

Adhikari M., Arora R., Chawla R., Sharma J., Dhaker A. S., Gupta D., Dubey N., Raj Kumar R., Ivanov V., Gadjeva V., Gevrenova R., and Sharma R. K. (2010), Evaluation of silymarin as a promising radioprotector. Z. Naturforsch. 65c, 337-346.

Arora R. (2008), Herbal Radiomodulators: Applications in Medicine, Homeland Defence and Space. CABI Publishing, Wallingford, Oxon, UK, p. 332.

Arora R., Gupta D., Chawla R., Sagar R., Sharma A., Kumar R., Prasad J., Singh S., Samanta N., and Sharma R. K. (2005), Radioprotection by plant products: present status and future prospects. Phytother. Res. 19, $1-22$.

Arora R., Chawla R., Singh S., Sagar R. K., Kumar R., Sharma A. K., Singh S., Prasad J., Sharma R. K., and Tripathi R. P. (2006), Radioprotection by Himalayan high-altitude region plants. In: Herbal Drugs: A Twenty First Century Perspective (Sharma R. K. and Arora R., eds.). Jaypee Brothers Medical Publishers (P) Ltd., Delhi, India, pp. 301-325.

Arora R., Chawla R., Singh S., Sagar R. K., Kumar R., Sharma A., Prasad J., Singh S., Gurudatta G. U., and Sharma R. K. (2007), Bioprospection for radioprotective molecules from indigenous flora. In: Recent Progress in Medicinal Plants (Govil J. N., Singh V. K., and Bhardwaj R., eds.). Studium Press, LLC, Houston, TX, USA, pp. 179-219.

Chandhoke N. and Ray Ghatak B. J. (1975), Pharmacological investigations of angelicin - a tranquillosedative and anticonvulsant. Ind. J. Med. Res. 63, 833.

Chawla R., Arora R., Kumar R., Sharma A., Prasad J., Singh S., Sagar R., Chaudhary P., Shukla S., Kaur G., Sharma R. K., Puri S. C., Dhar K. L., Handa G., Gupta V. K., and Qazi G. N. (2005), Antioxidant activity of fractionated extracts of rhizomes of high-altitude Podophyllum hexandrum: Role in radiation protection. Mol. Cell. Biochem. 273, 193-208.

Cousins M., Adelberg J., and Chenb F. (2007), Antioxidant capacity of fresh and dried rhizomes from four clones of turmeric (Curcuma longa L.) grown in vitro. Ind. Crop. Prod. 25, 129-135.

Cuendet M., Hostettmann K., and Potterat O. (1977), Irioid glucosides with free radical scavenging prop- ence, Bulgaria is gratefully acknowledged. Thanks are due to the Director, INMAS, Delhi, India, and the Rector, Trakia University, Stara Zagora, Bulgaria, for providing research facilities. Atlar Singh Dhaker is grateful to ICMR for providing a Senior Research Fellowship (SRF), while Jyoti Sharma and Manish Adhikari are thankful to DRDO for providing research fellowships.

erties from Fagraea blumei. Helv. Chim. Acta 80, $1144-1152$

Daice J. V. and Lewis S. M. (1995), Practical Hematology, $8^{\text {th }}$ ed. Churchill Livingstone, Edinburgh, UK.

Gandhi N. M. and Nair C. K. K. (2005), Protection of DNA and membrane from gamma radiation induced damage by gallic acid. Mol. Cell. Biochem. 278, 111-117.

Grant W. $3^{\text {rd }}$, Cundiff J., Hanson W., Gagnon W., and Shalek R. (2008), Calibration instrumentation used by the AAPM radiological physics center. Med. Phys. 3, 353-354.

Green L. C., Wagner D. A., Glogowski J., Skipper P. L., Wishnok J. S., and Tannenbaum S. R. (1982), Analysis of nitrate, nitrite and $\left[{ }^{15} \mathrm{~N}\right]$ nitrate in biological fluids. Anal. Biochem. 126, 131-138.

Gupta B. K., Gupta G. K., Dhar K. L., and Atal C. K. (1979), The essential oil from the seeds of P. corylifolia. Indian Perfum. 23, 174.

Halliwell B. and Gutteridge J. M. C. (1990), Role of free radicals and catalytic metal ions in human disease: an overview. Methods Enzymol. 186, 1-85.

Halliwell B. and Chirico S. (1993), Lipid peroxidation: its mechanism, measurement, and significance. Am. J. Clin. Nutr. 57, 715-725.

Halliwell B., Gutteridge J. M. C., and Aruomas O. I. (1987), The deoxyribose method: A simple "testtube" assay for determination of rate constants for reactions of hydroxyl radicals. Anal. Biochem. 165, 215-219.

Kakkar P., Das B., and Viswanathan P. N. (1984), A modified spectrophotometric assay of superoxide dismutase. Ind. J. Biochem. Biophys. 2, 130-132.

Kapoor L. D. (2001), Handbook of Ayurvedic Medicinal Plants. CRC Press, Boca Raton, FL, USA, pp. $274-275$.

Lai L. S., Chou S. T., and Chao W. W. (2001), Studies on the antioxidative activities of Hsian-tsao (Meson procumbens Hemsl.) leaf gum. J. Agric. Food Chem. 49, $963-968$.

Latha P. G. and Panikkar K. R. (1999), Inhibition of chemical carcinogenesis by Psoralea corylifolia seeds. J. Ethnopharmacol. 68, 295-298.

Lee M. H., Kim J. Y., and Ryu J. H. (2005), Prenylflavones from Psoralea corylifolia inhibit nitric oxide synthase expression through the inhibition of I-kappa B-alpha degradation in activated microglial cells. Biol. Pharm. Bull. 28, 2253-2257.

Liu R., Li A., Sun A. L., and Kong L. (2004), Preparative isolation and purification of psoralen and isopsoralen 
from Psoralea corylifolia by high-speed counter-current chromatography. J. Chromatogr. A 1057, 225-228.

Matthäus B. (2002), Antioxidant activity of extracts obtained from residues of different oilseeds. J. Agric. Food Chem. 50, 3444-3452.

Miura H., Nishida H., and Linuma M. (1996), Effect of crude fractions of Psoralea corylifolia seed extract on bone calcification. Planta Med. 62, 150-153.

New R. R. C., Rickwood D., and Hames B. D. (1990), Liposomes - A Practical Approach. IRL Press, Oxford, UK.

Oyaziu M. (1986), Antioxidative activity of browning products of glucosamine fractionated by organic solvent and thin layer chromatography. Nippon Shokuhin Kogyo Gakkai-Shi 35, 771-775.

Panda A. K. (2005), The medico historical perspective of vitiligo. Bull. Indian Inst. Hist. Med. Hyderabad 35, $41-46$.

Peng J. Y., Fan G. R., and Wu Y. T. (2006), Preparative isolation of four new and two known flavonoids from the leaf of Patrinia villosa Juss. by counter-current chromatography and evaluation of their anticancer activities in vitro. J. Chromatogr. A 1115, 103-111.

Rani P., Unni K. M., and Karthikeyan J. (2004), Evaluation of antioxidant properties of berries. Indian J. Clin. Biochem. 19, 103-110.

Rathore N., John S., Kale M., and Bhatnagar D. (1998), Lipid peroxidation and antioxidant enzymes in isoproterenol induced oxidative stress in rat tissue. Pharmacol. Res. 38, 297-303.

Ryu S. Y., Choi S. U., Lee C., and Zee O. P. (1992), Antitumor activity of Psoralea corylifolia. Arch. Pharm. Res. 15, 356-359.

Sagar R. K., Chawla R., Arora R., Singh S., Krishna B., Sharma R. K., Puri S. C., Singh P., Kumar R., Sharma A. K., Singh S., Prasad J., Gupta V., Ahmed B., Dhar K. L., Khan H. A., Gupta M. L., and Qazi G. N. (2006), Protection of the hemopoietic system by Podophyllum hexandrum against gamma radiationinduced damage. Planta Med. 72, 114-20.
Saito Y., Nishio K., Ogawa Y., Kinumi T., Yoshida Y., Masuo Y., and Niki E. (2007), Molecular mechanisms of 6-hydroxydopamine-induced cytotoxicity in $\mathrm{PCl} 2$ cells: Involvement of hydrogen peroxide-dependent and -independent action. Free Rad. Biol. Med. 42, $675-685$.

Sambrook K. J., Frisch E. F., and Maniatis T. (1989), Molecular Cloning: A Laboratory Manual, $2^{\text {nd }}$ ed. Cold Spring Harbor Laboratory Press, Cold Spring Harbor, USA.

Sies H. (1993), Strategies of antioxidant defense. Eur. J. Biochem. 215, 213-221.

Singleton V. L. and Rossi J. A. (1965), Colorimetry of total phenolics with phosphomolybdic acid-phosphotungstic acid reagents. Am. J. Enol. Vitic. 16, 144-158.

Srour M. A., Bilto Y. Y., Juma M., and Irhimeh M. R. (2000), Exposure of human erythrocytes to oxygen radicals causes loss of deformability, increased osmotic fragility, lipid peroxidation and protein degradation. Clin. Hemorheol. Microcirc. 23, 13-21.

Tsai W. J., Hsin W. C., and Chen C. C. (1996), Antiplatelet flavonoids from seeds of Psoralea corylifolia. J. Nat. Prod. 59, 671-672.

Wang Y., Hong C., Zhou C., Xu D., Qu H., and Cheng Y. (2009), Screening antitumor compounds psoralen and isopsoralen from Psoralea corylifolia L. seeds. Evidence Based Complementary and Alternative Medicine (Epub ahead of print). doi: 10-1093/ecam/ nen087.

Yankov K. (1998), Evaluation of some dynamics characteristics of transient processes. Proceedings of the 12th International Conference SAER'98, September 19-20, 1998, St. Konstantin Resort, Varna, Bulgaria, pp. $113-117$

Zaidi S. F. H., Yamada K., Kadowaki M., Usmanghani K., and Sugiyama T. (2009), Bactericidal activity of medicinal plants, employed for the treatment of gastrointestinal ailments, against Helicobacter pylori. J. Ethnopharmacol. 121, 286-291. 